\title{
EDITORIAL
}

\section{Which patients with rheumatoid arthritis are still working?}

\author{
Till Uhlig* \\ See related research by Sokka et al., http://arthritis-research.com/content/12/2/R42
}

\begin{abstract}
In the light of improved and costly treatment for rheumatoid arthritis (RA), the evaluation of work disability has gained increased attention. The assumption that better treatment of RA leads to increased work participation has not yet been supported by sufficient evidence. Differences in RArelated work disability have been observed between countries, also indicating an influence of non-diseaserelated macroeconomic factors. Work disability results from a complex interaction between a clinical disease, sociodemographic variables, macroeconomic conditions, and personal factors. Some of these factors are modifiable, while others are not.
\end{abstract}

During the past decade, the advent and accessibility of effective drugs has improved our ability to reduce rheumatoid arthritis (RA) disease activity and, hence, the consequences of inflammatory rheumatic joint diseases. One of these consequences is work disability, which is common in RA. Work disability across a number of countries has very recently been examined by Sokka and collaborators [1]. Rates of work disability are higher in people with RA than in the general population when adjusting for age and gender [2]. From a societal perspective it is important to evaluate if work disability in RA can be reduced alongside the proven clinical effectiveness of biologic drugs and other advances in treating and caring for patients with RA, which has alleviated the disease burden in recent years [3].

Most readers of this editorial probably work to give life a meaning, not only to make a living. Being employed may have positive effects on a person's quality of life, but if the work environment is experienced as less

*Correspondence: till.uhlig@diakonsyk.no

Department of Rheumatology, Diakonhjemmet Hospital, N-0319 Oslo, Norway satisfactory, there may be negative effects on health status. There is no reason why this should not also be the case for patients with RA.

Why is work disability increased in RA? People with RA who are work disabled have worse quality of life and more joint involvement, radiographic damage, disease activity, physical disability measured by Health Assessment Questionnaire (HAQ) and presence of rheumatoid factor than people with RA who are working. Similar findings concerning quality of life are observed in ankylosing spondylitis [4]. Beyond disease-related factors, demographic characteristics, such as age, sex, occupation, and level of education, influence work status.

As clinicians we may intuitively form an opinion on work prognosis when we for the first time treat a patient suffering from RA. Our perception may, in addition to disease-related factors and known demographic characteristics, also be influenced by the type of work and the personality traits of the patient. Work ability depends on physical factors related to work demands [5], but also on psychological factors, such as learned helplessness. Learned helplessness corresponds to the belief that nothing can be done to resolve a problem and was identified as an independent predictor of work disability in a prospective study with RA patients [6]. Development of individual coping skills are therefore important once a patient with RA is confronted with a threatened gap between work demands and work ability. Other important non-medical efforts include changes at the work place, provided patients inform their employer, and themselves accept a need for such changes [7].

The influence of different societal settings on work disability has so far not been satisfactorily researched using the same methodology in different countries. In their report Sokka and co-workers [1] examined workrelated factors in the QUEST collaboration by means of a cross-sectional assessment of RA patients in a number of European as well as North- and South-American countries. Results showed a similar pattern of work participation 2 and 5 years after the onset of RA symptoms independent of whether patients lived in more 
wealthy countries with a higher gross domestic product (GDP) or those with a lower GDP. Generally, better clinical status was seen in those patients still working, but a striking finding was that patients who stopped working in high-GDP countries had better or similar clinical status as judged by physical disability and disease activity variables to those still working in countries with a low GPD. The results demonstrate an influence of macroeconomic factors not related to the disease; in other words, RA patients in poor countries work with more disease activity and suffering than those who are work disabled in wealthier countries.

The study also shows that work disability remains high even when disease onset occurred after the year 2000, when biologics against RA had become available. This does not support optimistic views that the amounts of money spent on biological drugs would be balanced by money earned due to declining work disability. Reducing disease activity in RA alone does not bring the RA patient back to work even though the patient may have increased quality of life. There may be a number of reasons for this, one being that temporary work disability is a risk factor for permanent work disability, and biological drugs are not necessarily initiated when patients are most vulnerable to losing their work.

With all the due caveats applicable to this study, including lack of detail when assessing work disability, limitations in the comparisons between different countries, and the cross-sectional research design, it points towards the importance of a country's wealth when it comes to RA-related work disability. At the same time, work disability rates were surprisingly similar in poor and rich countries. Another study comparing patients with RA from the United States and Finland [8] found that the latter had better scores for functional status, pain and global status, but a higher risk of being work disabled, which most likely reflected differences in the social systems in the two countries.

From what is stated above, work disability in RA results from an interaction between RA disease, sociodemographic variables, macroeconomic conditions, and personal factors. Some of these factors are modifiable, others are not.
We still need to learn more about which factors are facilitators and barriers for work ability in RA patients, but the demonstrated societal influence on work disability should alert not only those actively involved in decisions within and about national healthcare systems, but also increase our efforts to reduce inequity in care for RA.

\section{Abbreviations}

$\mathrm{GDP}=$ gross domestic product; $\mathrm{RA}=$ rheumatoid arthritis.

\section{Competing interests}

The author declares that he has no competing interests.

Published: 26 April 2010

References

1. Sokka T, Kautiainen $H$, Pincus T, Verstappen SM, Aggarwal A, Alten R, Andersone D, Badsha H, Baecklund E, Belmonte M, Craig-Müller J, da Mota LM, Dimic A, Fathi NA, Ferraccioli G, Fukuda W, Géher P, Gogus F, HajjajHassouni N, Hamoud H, Haugeberg G, Henrohn D, Horslev-Petersen K, Ionescu R, Karateew D, Kuuse R, Laurindo IM, Lazovskis J, Luukkainen R, Mofti A, et al:: Work disability remains a major problem in rheumatoid arthritis in the 2000s: data from 32 countries in the QUEST-RA study. Arthritis Res Ther 2010, 12:R42.

2. Verstappen SM, Boonen A, Bijlsma JW, Buskens E, Verkleij H, Schenk Y, van Albada-Kuipers GA, Hofman DM, Jacobson JW; Utrecht Theumatoid Arthritis Cohort Study Group: Working status among Dutch patients with rheumatoid arthritis: work disability and working conditions. Rheumatology (Oxford) 2005, 44:202-206.

3. Uhlig T, Heiberg T, Mowinckel P, Kvien TK: Rheumatoid arthritis is milder in the new millennium: Health status in RA patients 1994-2004. Ann Rheum Dis 2008, 67:1710-1715.

4. Chorus AM, Miedema HS, Boonen A, van der LS: Quality of life and work in patients with rheumatoid arthritis and ankylosing spondylitis of working age. Ann Rheum Dis 2003, 62:1178-1184.

5. Young A, Dixey J, Kulinskaya E, Cox N, Davies P, Devlin J, Emery P, Gough A, James D, Prouse P, Williams P, Winfield J: Which patients stop working because of rheumatoid arthritis? Results of five years' follow up in 732 patients from the Early RA Study (ERAS). Ann Rheum Dis 2002, 61:335-340.

6. Ødegård S, Kvien TK, Finset A, Uhlig T: Physical and psychological predictors for word disability over seven years in patients with rheumatoid arthritis. Scand J Rheumatol 2005, 34:441-447.

7. Allaire $\mathrm{SH}$ : Update on work disability in rheumatic diseases. Curr Opin Rheumatol 2001, 13:93-98.

8. Chung CP, Sokka T, Arbogast PG, Pincus T: Work disability in early rheumatoid arthritis: higher rates but better clinical status in Finland compared with the US. Ann Rheum Dis 2006, 65:1653-1657.

doi:10.1186/ar2979

Cite this article as: Uhlig T: Which patients with rheumatoid arthritis are still working? Arthritis Research \& Therapy 2010, 12:114. 